\title{
EDITORIAL
}

\section{Revista de Trabajo Social: 50 años al servicio de la disciplina}

\author{
Liliana Guerra Aburto \\ Asistente Social, Magister en Trabajo Social, Doctora en Estudios Latinoamericanos \\ Escuela de Trabajo Social PUCCH \\ Santiago, Chile \\ ldguerra@uc.cl \\ https://orcid.org/0000-0002-8422-6634
}

\author{
Alejandra Rasse Figueroa \\ Socióloga, Magister en Sociología, Doctora en Arquitectura y Estudios Urbanos \\ Escuela de Trabajo Social PUCCH, Centro de Desarrollo Urbano Sustentable CEDEUS \\ Santiago, Chile \\ Autor para correspondencia: arasse@uc.cl \\ https://orcid.org/0000-0003-0625-8021
}

Vivimos tiempos complejos y desafiantes. En el curso de dos años, hemos sido testigos de crisis sociales y políticas en diversos países de América Latina, que han impugnado tanto las formas institucionales actuales como los modelos que las sostienen, no solo en lo económico, sino también en lo social y cultural. La crisis socio-sanitaria, desatada por la pandemia de COVID 19, ha transformado radicalmente nuestra vida cotidiana y las formas en que nos relacionamos. Además, lo que durante décadas llamamos vulnerabilidad, hoy se ha vuelto pobreza efectiva. Por último, la crisis climática que enfrentamos confronta el modelo civilizatorio en que estamos envueltos, cuestionando en profundidad la forma en que, por muchos años, entendimos y experimentamos: nuestro planeta, la naturaleza, la humanidad y su sustento, y en especial, las ideas de progreso, desarrollo y bienestar.

En este escenario, las Ciencias Sociales se encuentran en tensión. Por un lado, resultan centrales para poder comprender y transformar prácticas, resignificar y recrear instituciones, y evaluar y repensar modelos y formas de hacer. Por otro lado, están desafiadas a repensarse a sí mismas, cuestionar sus modelos y conceptos, y volver a construirse: las ciencias sociales forman parte de esta sociedad que atraviesa múltiples crisis.
En este marco, el Trabajo Social juega un rol central: el corazón disciplinar se sitúa más allá del pensamiento crítico, y lo hace directamente en la transformación social. Una trasformación social en la que, trabajadoras y trabajadores sociales, participamos cotidianamente a través de la relación cara a cara con las personas, reconociendo las dinámicas humanas y sociales que impactan sus vidas; en espacios comunitarios y organizacionales, así como también en la propuesta de políticas públicas. Desde siempre la reflexión de la disciplina ha incorporado la pregunta por la posicionalidad ética y política, y en su horizonte permanentemente encontramos la búsqueda de la dignidad. Las trabajadoras y trabajadores sociales, por vocación y profesión, estamos siempre en relación directa con quienes experimentan la violencia, la discriminación, la exclusión y la pobreza, así como con quienes se movilizan, se organizan, buscan e inciden en los procesos de cambio. El debate disciplinar y el debate conceptual se producen desde esta experiencia profesional concreta, situada, tensionada y en conflicto, que permite a la disciplina, confrontar continuamente sus perspectivas y modelos, cuestionar sus conceptos, transformar y transformarse.

La Revista de Trabajo Social, en sus 50 años de vida, ha sido históricamente un lugar para la reflexión dis- 
ciplinar desde y hacia los campos de desempeño profesional. El Trabajo Social, ahí donde se desenvuelve, identifica límites, levanta cuestionamientos, e instala innovaciones. Desde este convencimiento, a partir de este número buscamos dar énfasis a esta identidad, añadiendo a la tradicional sección de artículos científicos, una sección de análisis de casos, que permita discutir programas, políticas o proyectos, y una sección de reseña, que visibilice y debata en torno a la producción en formato libro en el marco del interés disciplinar. Abrirá cada número una editorial referente a las diversas discusiones, temas y dilemas propios del ejercicio del Trabajo Social contemporáneo, con una mirada nacional, pero tambien de quienes lo ejercen en diversas partes del mundo.
Buscamos ser un espacio para debatir lo que desde el Trabajo Social se investiga, pero también para hacer circular aquella producción de conocimiento imbricada en la praxis, que proviene de lo que se interviene, se trabaja, se innova y se hace.

Desde esta perspectiva, nos unimos desde nuestra historia como Revista de Trabajo Social al conjunto de revistas que, en los últimos años, desde América Latina, Hispanoamérica y Chile, están haciendo un esfuerzo por ampliar y profundizar la discusión y aporte disciplinar a las Ciencias Sociales y las políticas públicas. En tiempos de crisis, podrán leer en nuestras páginas conocimiento situado, critica social y experiencias de transformación. 